\title{
O COMÉRCIO INTERNACIONAL E O MEIO AMBIENTE. O COMÉRCIO COMO INSTRUMENTO DA CONCRETIZAÇÃO DO PRINCÍPIO DO DESENVOLVIMENTO SUSTENTÁVEL
}

\section{THE INTERNATIONAL TRADE AND THE ENVIRONMENT. TRADE AS AN INSTRUMENT FOR THE CONCRETION OF THE PRINCIPLE OF SUSTAINABLE DEVELOPMENT}

\author{
${ }^{1}$ Mariana Battochio Stuart \\ ${ }^{2}$ Norton Eduardo Brandemburg
}

\section{RESUMO}

O presente estudo se propõe a traçar um panorama da regulação do comércio internacional na atualidade, com ênfase para a atuação da Organização Mundial do Comércio (OMC), que envolve a concretização do desenvolvimento sustentável dos países. Utilizou-se de pesquisa histórico-bibliográfica e método indutivo para demonstrar a capacidade do comércio internacional na indução de condutas positivas à preservação do meio ambiente, através de decisões do Órgão de Solução de Controvérsia da OMC que incentivem a utilização de métodos e processos de produção que reduzam os impactos ambientais, mantendo a concorrência e competitividade dos produtos, além da possibilidade de responsabilização jus cogens.

PALAVRAS-CHAVES: Direito Internacional Ambiental; Direito Ambiental Econômico; Comércio Internacional

\section{ABSTRACT}

The present study proposes to outline a panorama of international trade regulation, with emphasis on the work of the World Trade Organization (WTO), which involves achieving the sustainable development of countries. Historical-bibliographic research and an inductive method have been used to demonstrate the ability of international trade to induce positive behavior towards the preservation of the environment through decisions of the WTO Dispute Settlement Body that encourage the use of production methods and processes That reduce environmental impacts, maintaining competition and competitiveness of products, and the possibility of jus cogens accountability.

\footnotetext{
${ }^{1}$ Doutoranda em Direito pela Universidad Nacional de Córdoba - UNC, (Argentina). Mestre em Direitos Difusos e Especialista em Direito Ambiental pela Pontifícia Universidade Católica de São Paulo - PUC-SP, São Paulo, SP, (Brasil). Advogada. E-mail.: marianabattochio@ hotmail.com.

${ }^{2}$ Doutorando pela Universidad Nacional de Córdoba - UNC, Argentina. Especialista em Direito Público pela Universidade Potiguar - UnP/RN, Rio Grande do Norte, RN, (Brasil). Bacharelando em Ciências Econômicas pela Universidade Federal do Mato Grosso do Sul - UFMS, Mato Grosso do Sul, MS, (Brasil). Servidor Público Federal. E-mail.:
}

Revista Brasileira de Direito Internacional le-SSN: 2526-0219| Curitiba | v. 2 | n. 2 | p. 173 - 192 |

Jul/Dez. 2016. 
KEYWORDS: International Environmental Law; Economic Environmental Law; International Trade

\section{INTRODUÇÃO}

Nos últimos anos, a sociedade internacional ${ }^{3}$ experimentou uma alteração no comércio internacional. O fenômeno da globalização refletiu profundamente nas relações comerciais entre os países, principalmente com a facilitação ocorrida nos transportes e nas comunicações, deixando o mundo com um aspecto menor e comprovando a teoria da compressão do tempo-espaço de Harvey ${ }^{4}$.

Atualmente, na pós-modernidade ${ }^{5}$, o comércio internacional é caracterizado por uma ampliação no seu conceito. Hodiernamente abrange não apenas a importação e exportação de bens agrícolas e industriais, mas abarca também os serviços nos mais diversos setores, tais como transportes, financeiro, telecomunicações, incluindo até mesmo os serviços profissionais e a propriedade intelectual.

Em paralelo, as questões ambientais se tornaram pauta de todos os governos mundiais. A preservação dos recursos hídricos, a gestão adequada dos resíduos sólidos, a compatibilização do crescimento econômico com a higidez ambiental são algumas das preocupações que envolvem a temática.

Isso porque os danos advindos do mal uso dos recursos naturais são transfronteiriços, ou seja, extrapolam as barreiras geográficas e trazem consequências a toda população global.

Considerando o equilíbrio ecológico como direito humano de terceira dimensão ${ }^{6}$, sua ofensa pode gerar punição não só no âmbito interno dos Estados, como também no âmbito internacional.

\footnotetext{
${ }^{3}$ No presente trabalho utilizar-se-á o termo sociedade internacional para representar a sociedade formada pelos Estados, organismos internacionais e indivíduos, que se constitui como universal, igualitária, aberta, sem organização rígida e de direito originário. Nesse sentido, ver HUSEK, 2012, p.52.

${ }^{4}$ Segundo Harvey, a vida pós-moderna está caracterizada por uma sociedade global sem fronteiras. Foi alterado o sentido do espaço global e isso acarretou uma mudança no sentido do tempo. A transformação do mundo e das relações sociais trazem mudanças na visão que se tem a respeito da ideia de tempo e do espaço (HARVEY, 2008, P. 257-276).

${ }^{5} \mathrm{O}$ conceito de pós-modernidade, no presente trabalho, será o apresentado por Bauman. Conforme este autor a sociedade pós-moderna é uma sociedade de consumo conduzida pelo Mercado e marcada pela relativização da atuação estatal e da privatização da ordem. Nela os indivíduos que não são capazes de acompanhar a lógica consumista são tidos como "consumidores falhos". No modelo de vida pós-moderno a incerteza e a insegurança ocupam lugares cada vez mais centrais (BAUMAN, 1998).

6 Acerca da evolução das dimensões dos Direitos Humanos: BONAVIDES, 1993, p. 474; SARLET,1998, p. 48.
}

Revista Brasileira de Direito Internacional le-SSN: 2526-0219| Curitiba | v. 2 | n. 2 | p. 173 - 192 | Jul/Dez. 2016. 
Assim, a correta atuação do comércio internacional pode induzir condutas positivas à preservação dos recursos naturais.

Para se alcançar a problemática proposta, a metodologia adotada no presente estudo será a da pesquisa histórico-bibliográfica, sendo, ainda, utilizado o método indutivo para o alcance das principais conclusões.

\section{O COMÉRCIO INTERNACIONAL NA PÓS-MODERNIDADE}

O comércio internacional pode ser entendido atualmente como as relações que envolvem a produção, compra, venda, troca ou qualquer outro tipo de transação efetuada entre diferentes países, gerando um consumo de bens e serviços.

Em razão da impossibilidade de um país ser autossuficiente em toda sua demanda, a qual foi incrementada com a procura de novos produtos - decorrente principalmente pela facilidade de troca de informações - a prática do comércio internacional tem crescido continuamente.

Por isso, a globalização potencializou o comércio internacional, uma vez que, com o crescente desenvolvimento e facilitação dos transportes e comunicações, os produtores e prestadores de serviço foram submetidos a um grau de concorrência mundial, obrigando cada país a se especializar em determinados segmentos, demandando os demais setores do comércio externo.

\subsection{Panorama da regulação do comércio internacional}

O surgimento e a evolução do comércio internacional gerou a necessidade de sua regulação, que ocorreu inicialmente de forma bilateral, com dois países regulamentando pontos específicos do comércio entre eles. Posteriormente, com o aumento e desenvolvimento do comércio internacional, houve a ampliação dessa regulação, criando-se uma estrutura regulatória multilateral, alcançando os mercados regionais e o comércio a nível mundial.

Nesse ponto, a Organização Mundial do Comércio possui papel de destaque na atividade reguladora do comércio internacional, pois suas normas buscam regulamentar e liberalizar as trocas entre as partes contratantes a partir de um conjunto de regras baseadas em 
princípios fundamentais, impedindo que as regras de controle dos fluxos comerciais sejam utilizadas como barreiras ao comércio internacional (BARACAT, 2012).

As normas jurídicas aplicáveis correspondem às oito rodadas de negociação ocorridas no GATT (General Agreement on Tariffs and Trade ou Acordo Geral sobre Tarifas e Comércio), já encerradas, além da última rodada de negociação, ainda em andamento, denominada Rodada Doha, e que é a primeira rodada concebida após a criação da OMC.

Conforme se extrai do próprio acordo constitutivo da $\mathrm{OMC}$, seu sistema jurídico está fundamentado nos seguintes princípios gerais: (i) tratamento nacional, (ii) tratamento geral da nação mais favorecida, (iii) eliminação das restrições quantitativas e (iv) transparência.

O 'tratamento nacional' é a regra estabelecida para proibir a discriminação entre produtos produzidos internamente e os importados por outros países, de forma que as tarifações internas não podem ser aplicadas em detrimento dos produtos importados.

O 'tratamento geral da nação mais favorecida' é a regra fundamental que visa evitar a discriminação entre os membros desta Organização Internacional, de modo que toda vantagem, imunidade, privilégio ou favor, são estendidos aos produtos considerados similares, de todas as outras partes, imediatamente.

Por sua vez, a 'eliminação das restrições quantitativas' constitui a regra que veda qualquer espécie de restrição não-tarifária que venha a ser estabelecida.

Em relação à regra fundamental da 'transparência', ela determina que todos os membros da OMC devem tornar públicas as suas leis, regulamentos, decisões judiciais, bem como qualquer outra medida, garantindo que todos os membros tenham conhecimento da exigência formulada, para viabilizar sua adequação aos novos padrões adotados.

No entanto, há exceções que podem ser tomadas pela OMC, desde que os requisitos previstos no GATT para cada caso em especial estejam presentes.

$\mathrm{O}$ primeiro destes privilégios que pode ser citado, está amparado pelo artigo XX do GATT. Ele envolve exceções gerais que podem ser tomadas para proteção do interesse público, da saúde, dos direitos do autor, do interesse cultural, paisagístico, dos recursos naturais, entre outros. Nestas exceções, especificamente, podem entrar medidas voltadas para a proteção do meio ambiente ecologicamente equilibrado.

Há, também, exceções que visam salvaguardar o balanço de pagamentos, disciplinadas nos artigos XII e XVIII do GATT, onde qualquer uma das partes contratantes pode restringir a quantidade ou o valor dos produtos importados, pelo tempo necessário para 
resolver uma crise, sendo que os países em desenvolvimento possuem regras especiais para resguardar seu balanço de pagamentos e para proteger suas indústrias.

Outras exceções que merecem destaque são as que envolvem medidas antidumping; as medidas compensatórias; e os tratamentos especiais e diferenciados para os países em desenvolvimento, de forma a garantir o seu crescimento.

É importante ressaltar que qualquer medida poderá ser questionada no Órgão de Solução de Controvérsia da OMC, que será provocado quando ocorrer a adoção de medidas em contrariedade com as normas dos tratados do sistema OMC por parte de algum dos seus membros.

Então, ante a existência de conflito ou de disputa comercial entre os membros que compõem a OMC, o Órgão de Solução de Controvérsia 'tem autoridade de instituir painéis de especialistas para analisar cada caso. Pode aceitar ou rejeitar os resultados de um painel. Também, monitora a implantação das recomendações e autoriza retaliações, quando um país não cumpre com as regras' (Portal Eletrônico do Ministério da Agricultura: OMC - Órgão de Solução de Controvérsias, acesso em 15 fev. 2016).

Dessa forma, o Órgão de Solução de Controvérsia possui posição de destaque na OMC, pois é o principal fiscalizador da aplicação das regras que incidem no comércio internacional.

\section{DIREITO INTERNACIONAL AMBIENTAL}

Como impacto indesejado da Revolução Industrial iniciada no Século XVIII na Inglaterra, é possível citar inúmeros desequilíbrios ecológicos. Se o aumento da produção através da industrialização veio atender à maior demanda e consumo decorrentes do crescimento populacional, em contrapartida os ecossistemas passaram a sofrer maior sobrecarga. De um lado, pela utilização em larga escala de recursos naturais, como matériaprima e outros insumos, inclusive para a geração de energia; e sem a preocupação com o esgotamento dos recursos não renováveis e com a capacidade limitada de regeneração dos recursos renováveis. De outro lado, pelo maior volume dos resíduos lançados, bem como pela maior durabilidade, toxicidade e periculosidade, notadamente dos resíduos sintéticos (YOSHIDA, 2009, p. 1180). 
Em 1972 surge um marco na história da proteção ambiental: a Conferência das Nações Unidas sobre Homem e Meio Ambiente ocorrida em Estocolmo, na Suécia. A Organização das Nações Unidas (ONU) realizou essa conferência para debater, pela primeira vez em âmbito global, as questões que envolviam o desenvolvimento econômico e a preservação dos recursos naturais.

Após este encontro entre as Nações, outras conferências foram realizadas visando a discussão do desenvolvimento econômico dos países em consonância com a preservação do meio ambiente.

Assim, a ONU incorporou mais uma função, qual seja, a preservação dos recursos naturais, por meio do Programa das Nações Unidas para o Meio Ambiente (PNUMA).

Essas conferências voltadas para a temática ambiental construíram uma disciplina autônoma intitulada de Direito Internacional do Meio Ambiente, como bem pondera o Professor Carlos Roberto Husek (2012, p.45):

Quando se fala em meio ambiente: mares despoluídos, rios com peixes, atmosfera limpa, conservação da camada de ozônio, despoluição visual, despoluição sonora, conservação da fauna e da flora, a preservação enfim da biosfera e o Direito Internacional está voltado para o meio ambiente. Também faz parte do Direito Internacional Público e dos próprios Direitos Humanos. Tanto os Direitos Humanos como o Direito do Meio Ambiente vêm arrimados em diversos textos internacionais $[\ldots]$.

\subsection{O Princípio do Desenvolvimento Sustentável em tratados internacionais}

A ideia do equilíbrio entre o meio ambiente, a economia e as questões sociais, foi delineada desde o ano de 1972 com a Primeira Conferência Mundial sobre o Homem e o Meio Ambiente, realizada pela ONU na cidade de Estocolmo na Suécia. Por essa razão, será necessário traçar um panorama histórico e evolutivo do conceito de desenvolvimento sustentável ao longo destes últimos quarenta anos de história do Direito Ambiental Internacional.

No ano de 1983, as Nações Unidas criaram a Comissão Mundial sobre o Meio Ambiente e Desenvolvimento, que foi presidida pela ex-Primeira Ministra da Noruega Gro Harlem Brundtland, médica especializada em saúde pública. Essa Comissão foi criada após a avaliação dos dez anos da Conferência de Estocolmo, com o objetivo de promover audiências em todo o mundo. De fato, foram realizadas reuniões públicas em regiões com diversos graus 
de desenvolvimento, possibilitando que diferentes grupos expressassem seus pontos de vista em relação às questões ambientais.

Como resultado formal das discussões realizadas pela Comissão Mundial sobre o Meio Ambiente e Desenvolvimento, foi publicado em 1987 o "Relatório Brundtland" ou "Informe Brundtland", também denominado "Nosso Futuro Comum", trazendo de maneira pioneira o termo desenvolvimento sustentável:

\begin{abstract}
O desenvolvimento sustentável é o desenvolvimento que encontra as necessidades atuais sem comprometer a habilidade das futuras gerações de atender suas próprias necessidades. (...) Na sua essência o Desenvolvimento Sustentável é um processo de mudança no qual a exploração dos recursos, o direcionamento dos investimentos, a orientação do desenvolvimento tecnológico e a mudança institucional estão em harmonia e reforçam o atual e futuro potencial para satisfazer as aspirações e necessidades humanas (Portal Eletrônico da ONU Brasil. Relatório Brundtland Nosso Futuro Comum, acesso em 26 abr. 2013).
\end{abstract}

Desse modo, a maior inovação trazida pelo documento Bruntland foi o seu novo olhar sobre o desenvolvimento, apontando a incompatibilidade entre desenvolvimento sustentável e os padrões de consumo e produção daquela época, trazendo à tona a necessidade de uma nova relação entre ser humano e meio ambiente.

Assim, o "Relatório Brundtland" é considerado a gênese do termo desenvolvimento sustentável.

Importante salientar que o relatório não sugere a estagnação do crescimento econômico, mas sim a conciliação entre questões ambientais e sociais: o desenvolvimento sustentável seria a manutenção dos recursos naturais ante o crescimento da produção de bens, cujo foco seria a melhoria das condições sociais.

$\mathrm{Na}$ concepção de alguns economistas, conforme explica a Professora Cristiane Derani, o desenvolvimento sustentável só é possível em um período de prosperidade econômica; isto é, depois que a população tenha conseguido adquirir uma quantidade ideal de bens de consumo, suficientes para a sua satisfação e bem estar (DERANI, 2009, p. 114).

A adoção desse pensamento seria demasiadamente simplista e reducionista, pois desconsideraria a possibilidade de um equilíbrio entre economia, meio ambiente e as questões sociais. Desse modo, os recursos ambientais seriam analisados por uma ótica unicamente funcionalista, como fonte de matérias-primas para produção de bens materiais de consumo, o que de fato não ocorre pois, além de os recursos naturais serem esgotáveis, o homem precisa do meio ambiente para que haja qualidade de vida e dignidade humana.

Revista Brasileira de Direito Internacional le-SSN: 2526-0219| Curitiba | v. 2 | n. 2 | p. 173 - 192 | Jul/Dez. 2016. 
Em suma, não se pode falar em vida no planeta sem o meio ambiente. Por essa razão, em contraposição ao entendimento dos economistas que não vislumbram a sustentabilidade sem que haja um nível social e econômico avançado, o entendimento de Cristiane Derani é pelo término da tensão entre economia e ecologia:

A política ambiental vinculada a uma política econômica, assentada nos pressupostos do desenvolvimento sustentável, é essencialmente uma estratégia de risco destinada a minimizar a tensão potencial entre desenvolvimento econômico e sustentabilidade ecológica (DERANI, 2009, p. 120-121).

Dessa maneira, a flexibilização entre o Direito Ambiental e o Direito Econômico é necessária para que o mercado seja consciente, cumprindo objetivos básicos de racionalização e democratização da atividade econômica, entendida como produção, reprodução e distribuição das riquezas. Assim, o objetivo é afastar uma prática utilitarista voltada apenas à eficiência da produção de bens.

Neste momento, é necessário ressaltar que a visão adotada neste trabalho está muito distante da Ecologia Profunda, movimento filosófico conhecido como Deep Ecology ${ }^{7}$. De acordo com esse movimento, o meio ambiente deveria ser preservado sem que houvesse interferência humana, ou seja, defendendo o crescimento econômico zero.

Diversamente, pretende-se trabalhar com um enfoque de proteção ambiental, não de preservação. Justamente para que a utilização dos recursos naturais não venha a comprometer o seu uso pelas gerações futuras, mas garantindo o aproveitamento pela presente geração.

Em linhas gerais, o que se busca é o postulado do "Tripé da Sustentabilidade", no qual estão contidos os aspectos econômicos, sociais e ambientais, em perfeito equilíbrio; viabilizando a vida humana na Terra, em sua concepção financeira, psicológica e vital.

Desse modo, o que se pretende delinear é uma visão de sustentabilidade e desenvolvimento econômico adequada ao postulado do "antropocentrismo alargado", em que

\footnotetext{
${ }^{7}$ Essa filosofia biocêntrica possui como fundador o filósofo norueguês Arne Naes e influenciou diretamente o surgimento dos movimentos ambientalistas. Defende o despertar de uma consciência ecológica e é vista como uma filosofia radical (RODRIGUES, consultado em 15.02.2016).

${ }^{8}$ Inicialmente denominado de Triple Bottom Line, o tripé da sustentabilidade é originalmente composto por 3 fatores: pessoas, planeta e lucro (CARVALHO, consultado em 15.02.2016).

${ }^{9}$ De acordo com José Rubens Morato Leite e Patryck de Araujo Ayala a Constituição Federal brasileira de 1988 adotou uma visão antropocentrista alargada do bem ambiental, estabelecendo "uma exigência de que cada geração legue à seguinte um nível de qualidade ambiental igual ao que recebeu da geração anterior" (LEITE e AYALA, 2001, p. 68). Acerca do conceito de antropocentrismo alargado (enlightened ou prudential anthropocentrism), Andrew Brennan e Yeuk-Sze Lo afirmam: it should be noted, however, that some theorists working in the field see no need to develop new, non-anthropocentric theories. Instead, they advocate what may be called enlightenedanthropocentrism (or, perhaps more appropriately called, Prudential anthropocentrism).
}

Revista Brasileira de Direito Internacional le-SSN: 2526-0219| Curitiba | v. 2 | n. 2 | p. 173 - 192 | Jul/Dez. 2016. 
a concepção humana é de inserção na natureza; aliando a economia, o mercado e as necessidades sociais à proteção do meio ambiente, de tal forma a superar o Antropocentrismo Clássico que dissociava o homem do meio ambiente.

Doravante, todas as vezes que as expressões desenvolvimento sustentável e sustentabilidade sejam empregadas neste trabalho, elas devem ser compreendidas dentro dessa visão, evitando o reducionismo voltado apenas à causa ambiental ou ao olhar econômico da causa. Isso porque, na sociedade pós-moderna, o consumo, as atividades industriais, a economia e o mercado detém papéis importantes para a evolução da raça humana. Então, apesar dessas atividades possuírem uma capacidade extremamente devastadoras ao meio ambiente, é possível a utilização racional dos recursos naturais, compatibilizando a economia com a proteção ao meio ambiente.

Tomando-se por base esta premissa, qual seja, a finalidade da ordem econômica que tem por fundamento assegurar a todos uma existência digna - a Constituição do Brasil, respeitando os pressupostos da livre iniciativa, elegeu por princípio, dentre outros, o respeito ao meio ambiente, no seu artigo 170, inciso VI. E, dentro desta realidade, podemos apontar pontos positivos da evolução tecnológica: a facilidade nas comunicações e o fácil acesso à informação, entre muitos outros aspectos.

No entanto, as mudanças climáticas, as catástrofes nucleares e outros incidentes nefastos para a população mundial e para o meio ambiente não podem ser desconsiderados. $\mathrm{O}$ que se propõe é o equilíbrio entre todos os fatores que compõem a vida do homem na sociedade: a economia, a preservação ambiental e as questões sociais.

Neste momento, faz-se necessário traçar um breve histórico sobre como a proteção do meio ambiente, aliada às questões sociais e econômicas, foi tratada ao longo dos últimos quarenta anos, desde a pioneira Conferência ocorrida em Estocolmo em 1972.

A princípio, na Conferência realizada pelas Nações Unidas na Suécia, criadora do Programa das Nações Unidas para o Meio Ambiente (PNUMA), não havia a expressão 'sustentabilidade' ou 'desenvolvimento sustentável'. No entanto, naquele momento já se falava na compatibilização entre os fatores formadores do Tripé da Sustentabilidade:

Meio ambiente, sociedade e economia: a proteção e o melhoramento do meio ambiente humano é uma questão fundamental que afeta o bem-estar dos povos e o

Briefly, this is the view that all the moral duties we have towards the environment are derived from our direct duties to its human inhabitants. Fonte: BRENNAN, consultado em 10.03.2016. 
desenvolvimento econômico do mundo inteiro, um desejo urgente dos povos de todo o mundo e um dever de todos os governos (Preâmbulo - Item n ${ }^{\circ} 3$ da Declaração de Estocolmo sobre Meio Ambiente Humano, acesso em 15 fev. 2016).

Assim, pode-se afirmar que o ideal de sustentabilidade, posteriormente traçado, considerou como primeiro postulado de proteção ao meio ambiente a não interferência no bem-estar da população e no desenvolvimento econômico da nação.

É importante ressaltar a influência do ecodesenvolvimento, termo delineado pelo economista francês Ignacy Sachs, cujo conceito foi originalmente concebido por Maurice Strong (SACHS, 1986, 1993). O ecodesenvolvimento influenciou diretamente a proteção dos recursos naturais na década de 1970, devido à importante participação do estudioso Ignacy Sachs na elaboração da Declaração da Conferência de Estocolmo.

De acordo com o ecodesenvolvimento, já eram considerados os direitos das gerações futuras e havia uma consciência sobre a importância da compatibilização do componente ambiental com o critério econômico, além da possibilidade da participação das comunidades locais nos processos de decisão, com o intuito de atingir o interesse comum.

No entanto, são apontadas as seguintes divergências entre o ecodesenvolvimento e o que hoje é conceituado como desenvolvimento sustentável: (i) a noção de justiça social, (ii) a questão do papel da tecnologia e (iii) diferenças estratégicas de política econômica (DIAS e TOSTES, acesso em 15 fev. 2016).

Em relação à 'justiça social', o desenvolvimento sustentável defende o crescimento econômico, fomentando a criação de tecnologias mais eficientes para que a produção dos bens de consumo polua cada vez menos. O ecodesenvolvimento, por sua vez, busca um teto para o consumo. O objetivo é nivelar, por baixo, o padrão de consumo de bens pela população, viabilizando a diminuição do consumo mundial.

Quanto à 'questão tecnológica', o ecodesenvolvimento intenta que a produção de tecnologias se adapte às condições do meio ambiente, de forma a alcançar sua conservação; o desenvolvimento sustentável, no entanto, busca novas tecnologias, cujos resultados permitam manter um patamar mínimo de proteção ao ecossistema.

Por fim, as 'estratégias políticas' entre desenvolvimento sustentável e ecodesenvolvimento também divergem. O ecodesenvolvimento critica o livre mercado, defendendo a participação do Estado nos movimentos sociais, enquanto o desenvolvimento sustentável defende uma economia liberal com expansão do mercado. 
Ressalte-se que, neste trabalho, a visão que se pretende adotar é a do desenvolvimento sustentável, por entender que é a vertente que melhor se compatibiliza com uma sociedade capitalista e com o modelo econômico adotado pelo Brasil.

Seguindo a ordem cronológica das Conferências realizadas pela ONU para as questões do meio ambiente, em 1982 foi realizado um encontro em Nairóbi, no Quênia, sede do PNUMA, com o objetivo de comemorar os dez anos da Conferência de Estocolmo. Infelizmente, nesta Conferência, pouco se avançou na causa ambiental. Os anos 1970 foram mundialmente difíceis em termos econômicos, deixando a questão dos recursos naturais em segundo plano. Nesse momento, não foram desenvolvidas novas concepções ou entendimentos sobre a compatibilização entre economia, questões sociais e proteção do meio ambiente.

No ano de 1983, como anteriormente citado, foi criada pela ONU a Comissão Mundial sobre o Meio Ambiente e Desenvolvimento, presidida pela ex-Primeira Ministra da Noruega, que resultou na publicação do Relatório Brundtland em 1987, fato que trouxe uma nova concepção sobre desenvolvimento sustentável, bastante utilizada atualmente.

Em 1992, a causa ambiental retomou o seu vigor, com ânimos renovados, com a ocorrência da Conferência Mundial para o Meio Ambiente e Desenvolvimento - ECO 92. Essa Conferência, realizada na cidade do Rio de Janeiro, trouxe documentos importantes que apontaram os princípios que devem gerir o Direito Ambiental, assumindo as metas de melhoria das condições ambientais mundiais ${ }^{10}$.

De acordo com o Princípio 03 da Declaração do Rio de Janeiro sobre Meio Ambiente e Desenvolvimento Sustentável, o desenvolvimento sustentável é visto como um dever ao "permitir que sejam atendidas equitativamente as necessidades de gerações presentes e futuras" (Declaração do Rio de Janeiro sobre Ambiente e Desenvolvimento, acesso em 15 fev. 2016). Por isso, em linhas gerais, a concepção do Relatório Brundtland e da ECO 92 são semelhantes, por defenderem o casamento da ecologia com a economia, tratando da questão social em dispositivos apartados.

Em 2002, ocorreu em Johannesburgo, na África do Sul, a Conferência denominada Rio+10, com a finalidade de discutir soluções propostas na Agenda 21, como tentativa de

\footnotetext{
${ }^{10}$ Os debates ocorridos na Conferência Mundial para o Meio Ambiente e Desenvolvimento - Eco 92, culminaram na elaboração dos seguintes documentos oficiais: (i) Carta da Terra, criada pela Declaração do Rio de Janeiro sobre Meio Ambiente e Desenvolvimento Sustentável; (ii) Agenda 21; (iii) Convenção sobre Diversidade Biológica; (iv) Convenção do Clima e (v) Declaração do Rio sobre Ambiente e Desenvolvimento.
}

Revista Brasileira de Direito Internacional le-SSN: 2526-0219| Curitiba | v. 2 | n. 2 | p. 173 - 192 | Jul/Dez. 2016. 
implementação das discussões da ECO 92. Nessa Conferência foi retomada a concepção de ecodesenvolvimento, defendendo um postulado de sustentabilidade social como evolução entre sociedade e natureza, numa tentativa de retorno à concepção original de Estocolmo em 1972.

No ano de 2012 foi realizada - novamente na cidade do Rio de Janeiro - a Conferência das Nações Unidas Sobre Desenvolvimento Sustentável, conhecida como Rio+20. É bem verdade que esta última Conferência foi muito criticada pela mídia sob o argumento de que nenhum compromisso efetivo foi assumido naquele momento. No entanto, não podemos deixar de salientar que essa Conferência gerou importantes compromissos, estimulando a criação de soluções sustentáveis para o setor de negócios (Portal Eletrônico do Governo sobre o Rio+20, acesso em 02 maio 2013).

Os líderes empresariais presentes na Conferência Rio+20 chegaram a um acordo sobre a construção de uma sustentabilidade corporativa, contribuindo para uma sustentabilidade global. Foi assinada uma Declaração entre os $C E O s^{11}$ das grandes companhias, com o compromisso de redução do consumo e restauração dos recursos minerais.

Em relação ao Desenvolvimento Sustentável, a definição assentada na Conferência Rio +20 foi a de que "desenvolvimento sustentável é o modelo que prevê a integração entre economia, sociedade e meio ambiente. Em outras palavras, é a noção de que o crescimento econômico deve levar em consideração a inclusão social e a proteção ambiental" (Portal Oficial da Conferência Rio+20, acesso em 15 fev. 2016).

Assim, o desenvolvimento sustentável se manteve como estratégia de tentativa de conciliação entre o crescimento econômico dos países e a preservação do meio ambiente em sua concepção original, buscando estabelecer uma nova sociedade para que as futuras gerações tenham a mesma possibilidade de usufruir dos recursos naturais que a nossa geração possui.

\subsection{A natureza de jus cogens do Princípio do Desenvolvimento Sustentável}

\footnotetext{
${ }^{11}$ Sigla inglesa que significa Chief Executive Officer. No Brasil a sigla é utilizada para diretores executivos de empresas que ocupam o topo da hierarquia societária.
} 
Apesar de todo o arcabouço da normativa internacional apresentado anteriormente o que corrobora não apenas a existência, mas também a importância do Direito ao Desenvolvimento Sustentável para a sociedade internacional - é possível alcançar o entendimento de que os dispositivos apresentados sejam válidos apenas aos Estados que ratificarem e adotarem os princípios do Direito ao Desenvolvimento então determinados.

Contudo, dado seu caráter de relevância para toda a Humanidade, é certo afirmar que a natureza do Direito ao Desenvolvimento Sustentável seja de jus $\operatorname{cogens}^{12}$. Em outras palavras, as diretrizes do Direito ao Desenvolvimento Sustentável são oponíveis a todos os Estados, independentemente da ratificação ou aceitação da normativa internacional condizente.

Aplicando-se tal entendimento, e considerando o conceito de jus cogens como um conceito em constante expansão (CANÇADO TRINDADE, 2010, p. 295), a responsabilização dos Estados no que tange a eventuais ações ou omissões contrárias ao equilíbrio ecológico planetário teria maior eficiência, garantindo, enfim, sua potencial evolução, assim como o possível atingimento das metas estabelecidas pelos Objetivos de Desenvolvimento do Milênio e pelos atuais Objetivos de Desenvolvimento Sustentável, ambos elaborados pela $\mathrm{ONU}^{13}$.

\section{O COMÉRCIO INTERNACIONAL COMO INDUTOR DO PRINCÍPIO DO DESENVOLVIMENTO SUSTENTÁVEL}

\footnotetext{
${ }^{12}$ O jus cogens encontra-se definido no artigo 53 da Convenção de Viena sobre o Direito dos Tratados, de 1969. Ainda, se aplica no presente trabalho a definição de jus cogens trazida por Cláudio Finkelstein, no sentido de que este é o nome dado à norma obrigatória e inderrogável, seja pela vontade dos Estados ou mesmo por sua imposição. Referido significado, assim, vai além da cogência comum a qualquer ordem jurídica, de maneira que o conceito de jus cogens é baseado em uma aceitação de valores fundamentais e superiores, por toda a comunidade internacional dentro do sistema, e que, em determinados aspectos, assemelham-se ao conceito de ordem pública internacional ou ordem pública na ordem jurídica interna. Por fim, entende também o autor que o jus cogens representa as normas fundamentais do Direito Internacional que se aplicam a todos os Estados, sem exceção e independentemente de sua vontade ou consentimento. A esse respeito, ver FINKELSTEIN, 2010, p. 144.

${ }^{13}$ Embora tivesse alcance programado para o final de 2015, continuam os esforços para o cumprimento dos Objetivos de Desenvolvimento do Milênio, mas agora alinhados com os novos Objetivos de Desenvolvimento Sustentável. Estes objetivos foram elaborados pela ONU através do documento "Transformando Nosso Mundo: A Agenda 2030 para o Desenvolvimento Sustentável", que consiste em 01 Declaração, 17 Objetivos de Desenvolvimento Sustentável e 169 metas, todos a serem cumpridos até o ano de 2030. Esse documento completo pode ser visto através do seguinte link: 〈www.pnud.org.br/Docs/Agenda2030completo_PtBR.pdf〉. Acesso em 15.02.2016.
}

Revista Brasileira de Direito Internacional le-SSN: 2526-0219| Curitiba | v. 2 | n. 2 | p. 173 - 192 | Jul/Dez. 2016. 
O comércio internacional tem grande importância para a preservação ambiental. Os acordos e tratados comerciais - bem como as restrições adotadas para restringir o comércio de bens e serviços que degradam o meio ambiente, ou até mesmo contrariam legislações ambientais nacionais ou regionais - efetuados entre os países, forçam o debate ambiental, colaborando com a conscientização econômica ambiental mundial.

Assim, é essencial que a OMC, como organização que regula o comércio internacional, assuma um papel de liderança na ampliação desse pensamento ambiental no capitalismo globalizado, utilizando seu sistema de solução de controvérsias, com as respectivas sanções e intervenções.

\subsection{Organização Mundial do Comércio (OMC) e o Meio Ambiente}

A ocorrência de uma restrição ao comércio internacional por parte de um país, sendo o caso de suposta violação a um tratado e que afete diretamente à liberdade comercial, gera a necessidade de uma intervenção por parte da OMC.

Assim sendo, a utilização de medidas ambientais em contrariedade com as normas da OMC pode levar um dos membros dessa Organização Internacional a um procedimento perante o Órgão de Solução de Controvérsias.

Tal procedimento busca apurar a eventual responsabilidade internacional e consequente imposição de sanção, conforme determinações do Órgão. Nessa hipótese, será diretamente atingido o patrimônio econômico daquele membro da OMC, bem como sua atividade comercial.

A seguir serão analisados os casos em que a OMC deverá intervir visando a proteção dos recursos ambientais.

Apesar de, anteriormente, o GATT, e hoje, a OMC, serem instituições competentes para tratar de questões relacionadas ao comércio internacional e, não especificamente ao meio ambiente, eles também podem incorporar aos debates sobre políticas comerciais as questões relacionadas ao desenvolvimento sustentável e aos bens ambientais.

Após a Conferência das Nações Unidas sobre o Desenvolvimento Humano, ocorrida no ano de 1992, na cidade de Estocolmo, Suécia, levantou-se o debate sobre a contradição existente entre o desenvolvimento econômico e financeiro das nações e a preservação dos seus recursos naturais.

Revista Brasileira de Direito Internacional le-SSN: 2526-0219| Curitiba | v. 2 | n. 2 | p. 173 - 192 | Jul/Dez. 2016. 
Por conta disto, o Meio Ambiente passou a integrar a pauta das principais discussões dos países. Questões como o aquecimento global, o desmatamento, a poluição hídrica, do solo e radioativa passaram a ser consideradas.

Esses, sem sombra de dúvida, foram os primeiros passos para a existência do hoje denominado Direito Ambiental, ramo do Direito voltado às questões dos recursos naturais e ao Desenvolvimento Sustentável.

A partir daí, nasceram, também, os questionamentos sobre o modelo econômico capitalista, o padrão de consumo da população mundial e o comportamento humano em relação aos bens naturais, bem como a viabilidade do meio ambiente continuar servindo de subsídio para manutenção deste estilo de vida.

Concluiu-se, através de debates e estudos multidisciplinares, que a escassez dos recursos naturais frente ao consumo exagerado, poderia inviabilizar a existência humana na terra, surgindo a ideia de preservação pelas presentes para as futuras gerações.

Sendo a OMC justamente a Organização Internacional que regulamenta as questões mundiais que envolvem o comércio, ela, através de seu Órgão de Solução de Controvérsias, detém o poder-dever de aplicar sanções e intervir no mercado econômico mundial, visando, exatamente essa proteção do meio ambiente.

É sabido que houve uma mudança de posicionamento, considerada muito positiva, comparando o GATT/1947 e a atual Organização Mundial do Comércio: enquanto o GATT possuía entre seus objetivos principais incentivar a 'utilização ótima dos recursos mundiais traduzida na liberação gradual do comércio internacional por meio da eliminação das barreiras à prática do livre comércio' (QUEIROZ, acesso em 15 fev. 2016), o preâmbulo da OMC incorpora a ideia de desenvolvimento sustentável determinando que:

\begin{abstract}
As partes reconhecem que as suas relações na área do comércio e das atividades econômicas devem ser conduzidas com vistas à melhoria dos padrões de vida, assegurando o pleno emprego e um crescimento amplo e estável do volume de renda real e demanda efetiva, e expandindo o uso ótimo dos recursos naturais de acordo com os objetivos do desenvolvimento sustentável, procurando proteger e preservar o ambiente e reforçar os meios de fazê-lo, de maneira consistente com as suas necessidades nos diversos níveis de desenvolvimento econômico ${ }^{14}$.
\end{abstract}

\footnotetext{
${ }^{14}$ Preâmbulo Tratado de Marrakesh que cria a OMC.
} 
Dessa forma, é possível perceber que, no momento da criação da OMC como Organização Internacional, foi incorporado ao sistema do GATT um espaço para se debater novos temas, entre eles o meio ambiente.

Por essa razão, foi criado em 1994 o Comitê de Comércio e Meio Ambiente (Committee on Trade and Environment - CTE) com o objetivo de 'identificar a relação entre medidas comerciais e medidas ambientais, para promover o desenvolvimento sustentável e fazer recomendações apropriadas sobre a possível necessidade de se modificar alguma provisão do sistema multilateral de comércio' (Portal Eletrônico da Organização Mundial do Comércio - OMC, acesso em 15 fev. 2016).

Assim, a proteção ambiental tornou-se um dos principais focos da OMC, em especial, com a Declaração Ministerial de Doha, que incluiu na sua agenda a proteção ambiental, em especial nos acordos celebrados pela OMC.

Outrossim, o Programa das Nações Unidas para o Meio Ambiente - PNUMA, contribui para que a OMC tenha uma tratativa adequada para a questão ambiental.

\section{CONCLUSÃO}

O presente trabalho demonstrou que o comércio internacional pode ser utilizado como ferramenta capaz de induzir condutas positivas à preservação da higidez ambiental, visando à concretização do desenvolvimento sustentável.

Por todo exposto, é necessária na Comunidade Internacional a adequação das regras que regem o comércio no âmbito internacional, com a compatibilização das normas protetivas ao meio ambiente, viabilizando o desenvolvimento sustentável das nações.

Para tanto, as decisões emanadas do Órgão de Solução de Controvérsia da OMC, referentes às questões que envolvem medidas ambientais com reflexo no comércio, devem levar em consideração a questão da proteção dos recursos naturais, contribuindo para o mútuo incentivo entre as práticas comerciais e aquelas destinadas ao meio ambiente. 
Assim, as decisões da OMC, em geral, são um instrumento fundamental, através do qual essa contribuição deve ocorrer, harmonizando os diferentes níveis de desenvolvimento econômico dos países e apontando os instrumentos mais pertinentes para a construção de uma política ambiental, que considere a relevância de sua aplicação para os interesses dos países.

A OMC deve criar normas objetivando incentivar seus membros para utilização de métodos e processos de produção que reduzam os impactos ambientais, sem alterar a concorrência e a competitividade de seus produtos.

Ainda, depreende-se do presente trabalho a existência de uma abordagem protetiva aos recursos naturais provenientes dos direitos humanos, reconhecendo primeiramente a obrigação legal dos Estados-parte em tratados internacionais voltada à referida temática.

Além disso, a elevação do Direito ao Desenvolvimento Sustentável à categoria de jus cogens permite que - não apenas os Estados-membros de tratados e convenções referidos, mas todos os sujeitos e atores que compõem a chamada sociedade internacional - possam ser responsabilizados em caso de eventual violação às regras do comércio. Referida responsabilização poderia ser feita não apenas pelos demais Estados pertencentes à sociedade internacional, mas também por órgãos internacionais judiciais ou extrajudiciais.

Conclui-se, também, que o princípio do Desenvolvimento Sustentável deve ser concebido como um valor absolutamente relevante quando confrontado com atividades que utilizem recursos ambientais, colocando-se sempre em pauta, os fundamentos éticos e antropocêntricos do princípio ora discutido.

Por fim, mediante a análise da prática internacional envolvendo o comércio internacional e o Direito Ambiental Internacional, o presente trabalho conclui pela viabilidade da aplicação do princípio do desenvolvimento sustentável pela práxis do Direito Internacional em tratados bilaterais ou multilaterais de comércio em prol do desenvolvimento da sociedade internacional. A inserção de cláusulas - ou mesmo capítulos - em tratados bilaterais ou multilaterais de comércio, relacionados à promoção do desenvolvimento sustentável, torna-se um excelente exemplo de que a preocupação prática com a promoção da higidez ambiental deve ser essencial para a concretização de uma sociedade internacional livre, justa e, finalmente, igualitária. E, com essa mesma lógica aplicada à proteção do meio ambiente, resta garantida a esperança de uma vida saudável em nosso planeta, sem obstar o crescimento econômico dos Estados. 


\section{REFERÊNCIAS}

BARACAT, Fabiano Augusto Piazza. A OMC e o Meio Ambiente. 1a ed. Campinas: Millennium Editora, 2012.

BAUMAN, Zygmunt. O mal-estar da pós-modernidade. Tradução Mauro Gama e Cláudia Martinelli Gama; revisão técnica Luís Carlos Fridman. Rio de Janeiro: Zahar, 1998.

BONAVIDES, Paulo. Curso de Direito Constitucional. São Paulo: Malheiros, 1993.

BRENNAN, Andrew; LO, Yeuk-Sze, Environmental Ethics, In The Stanford Encyclopedia of Philosophy -Fall 2011 Edition, Ed. Edward N. Zalta. Disponível em: <http://plato.stanford.edu/archives/fall2011/entries/ethics-environmental/>. Acesso em 10 mar. 2016.

CANÇADO TRINDADE, Antônio Augusto. International Law for Humankind: Towards a New Jus Gentium. The Hague Academy of International Law. The Netherlands: Martinus Nijhoff Publishers, 2010.

CARVALHO, Cristine. "Triple Botton Line” ou tripé da sustentabilidade. Disponível em: $<$ http://www.sustentabilidaderesultados.com.br/o-triple-bottom-line-e-a-sustentabilidadecorporativa/>. Acesso em 15 fev. 2016.

Declaração do Rio de Janeiro sobre Ambiente e Desenvolvimento. Disponível em: <http://www.mma.gov.br/port/sdi/ea/documentos/convs/decl_rio92.pdf>. Acesso em 15 fev. 2016.

DERANI, Cristiane. Direito Ambiental Econômico. $3^{\text {a }}$ Edição. São Paulo: Editora Saraiva: 2009.

DIAS, Guilherme Vieira; TOSTES, José Glauco Ribeiro. Desenvolvimento Sustentável: do Ecodesenvolvimento ao Capitalismo Verde. Disponível em: 
<http://www.socbrasileiradegeografia.com.br/revista_sbg/Artigos_arquivos/GUILHERME_ar tigo_SBG.pdf>. Acesso em 15 fev. 2016.

FINKELSTEIN, Cláudio. 'Jus cogens' como paradigma do metaconstitucionalismo de Direito Internacional. Tese de Livre-Docência em Direito Internacional Público, apresentada à Pontifícia Universidade Católica de São Paulo. São Paulo, 2010.

HAMM, Brigitte I. A Human Rights approach to development. Human Rights Quarterly. Vol. 23, No. 4. The Johns Hopkins University Press, 2001.

HARVEY, David. A condição pós-moderna. 17 ed. São Paulo: Loyola, 2008.

HUSEK, Carlos Roberto. Curso de Direito Internacional Público. $11^{\mathrm{a}}$ ed. São Paulo: LTR, 2012.

LEITE, José Rubens Morato; AYALA, Patryck de Araújo. A transdisciplinariedade do direito ambiental e sua equidade intergeracional. In Revista de Direito Ambiental. São Paulo: RT, abr/jun 2001.

Portal Eletrônico da ONU Brasil. Relatório Brundtland - Nosso Futuro Comum. Disponível em : 〈http://www.onu.org.br/a-onu-em-acao/a-onu-e-o-meio-ambiente>. Acesso em 26 abr. 2013.

Portal Eletrônico da Organização Mundial do Comércio - OMC. Disponível em: <http://www.wto.org/english/tratop_e/envir_e/issu5_e.htm>. Acesso em 15 fev. 2016.

Portal Eletrônico do Governo Sobre o Rio+20: Disponível em: <http://www.rio20.gov.br/sala_de_imprensa/noticias-nacionais1/economia-verde-poderiaretirar-milhoes-de-pessoas-da-pobreza>. Acesso em 02 maio 2013.

Portal Eletrônico do Ministério da Agricultura 'OMC - Órgão de Solução de Controvérsias'. Disponível em: <http://www.agricultura.gov.br/internacional/organizacao-mundial-docomercio-omc/orgao-de-solucao-de-controversias>. Acesso em 15 fev. 2016. 
Portal Oficial da Conferência Rio+20. Disponível em: <http://www.rio20.gov.br/clientes/rio20/rio20/sobre_a_rio_mais_20/desenvolvimentosustentavel.html>. Acesso em 15 fev. 2016.

Preâmbulo - Item $N^{o} 3$ da Declaração de Estocolmo sobre Meio Ambiente Humano Tradução Livre. Disponível em: 〈http://www.dhnet.org.br/direitos/sip/onu/doc/estoc72.htm>. Acesso em 15 fev. 2016.

QUEIROZ, Fábio Albergaria. Meio ambiente e comércio na agenda internacional: as questões ambientais nas negociações da OMC e dos blocos econômicos regionais. Disponível em: $\quad<$ http://www.scielo.br/scielo.php?script=sci_arttext\&pid=S1414753X2005000200007\&lng=pt\&nrm=iso\&tlng=pt>. Acesso em 15 fev. 2016.

RODRIGUES, Vera Mónica dos Santos. Deep Ecology: Princípios, Fundamentos e Fins. Disponível em: <http://run.unl.pt/bitstream/10362/7622/1/Tese\%20Mestrado\%20\%20Deep\%20Ecology.pdf>. Acesso em 15 fev. 2016.

SACHS, Ignacy. Ecodesenvolvimento: crescer sem destruir. Tradução de E. Araujo. São Paulo: Vértice, 1986.

Estratégias de transição para o Século XXI: desenvolvimento e meio ambiente. Prefácio: M. F. Strong. Tradução de Magda Lopes. São Paulo: Studio Nobel - Fundação do desenvolvimento administrativo (FUNDAP), 1993.

SARLET, Ingo Wolfgang. A Eficácia dos Direitos Fundamentais. Porto Alegre: Livraria do Advogado. 1998.

Transformando Nosso Mundo: A Agenda 2030 para o Desenvolvimento Sustentável. Disponível em: <www.pnud.org.br/Docs/Agenda2030completo_PtBR.pdf>. Acesso em 15 fev. 2016.

YOSHIDA, Consuelo Yatsuda Moromizato. Direitos fundamentais e meio ambiente. In: MIRANDA, Jorge; SILVA, Marco Antônio Marques da. Tratado luso-brasileiro da dignidade humana. 2. ed. São Paulo: Quartier Latin, 2009. 